\title{
Frequency distributions of some parameters of negative downward lightning flashes based on accurate-stroke-count studies
}

\author{
Maurício G. Ballarotti, ${ }^{1}$ Claudia Medeiros, ${ }^{1}$ Marcelo M. F. Saba, ${ }^{1}$ Wolfgang Schulz, ${ }^{2}$ \\ and Osmar Pinto Jr. ${ }^{1}$ \\ Received 8 November 2011; revised 9 January 2012; accepted 10 January 2012; published 29 March 2012. \\ [1] This paper presents some parameters of negative cloud-to-ground lightning flashes in \\ terms of frequency distribution. All data are based on so-called "accurate-stroke-count \\ studies" from different climatological regions in the world and were already published in \\ the literature with the exception of our measurements. We used GPS synchronized data \\ from two digital high-speed cameras (at 1-8,000 frames/sec). The parameters considered in \\ this study are: (1) continuing current duration, (2) time intervals between strokes, \\ (3) number of strokes per flash and (4) total flash duration. The analysis includes Berger's \\ data of Monte San Salvatore (Switzerland), which is the basis for lightning protection \\ standards. The comparison suggests that despite of overall agreement of those parameters \\ that some of them, currently used in protection standards, should be revised in order to \\ be more realistic.
}

Citation: Ballarotti, M. G., C. Medeiros, M. M. F. Saba, W. Schulz, and O. Pinto Jr. (2012), Frequency distributions of some parameters of negative downward lightning flashes based on accurate-stroke-count studies, J. Geophys. Res., 117, D06112, doi:10.1029/2011JD017135.

\section{Introduction}

[2] Lightning parameters are an important input for the conception of electric power systems. They have been analyzed mainly based on lightning current measurements at instrumented towers or measurements from rocket-triggered lightning. Lightning current measurements are especially important for the stroke characterization itself (e.g., peak current and current waveshape). A review of stroke parameters is given by Rakov and Uman [2003] and Chowdhuri et al. [2005]. A review of lightning interaction with power systems is given by, e.g., Rakov [2001], Ianoz [2007] and Samaras et al. [2007]. The influence of an instrumented tower on lightning parameters is generally not confirmed by observations [e.g., International Council on Large Electric Systems (CIGRE), 1997; Rakov, 2003; Visacro and Silveira, 2005]. Indirect estimation of lightning return-stroke current from remote electromagnetic field measurements is discussed, e.g., by Diendorfer et al. [1998].

[3] Directly measured current data obtained on Monte San Salvatore (Switzerland) by K. Berger and his colleagues are one of the basic inputs for the national and international standards on lightning protection. These measurements have been used to characterize not only the stroke but also some flash parameters that are important for engineering

\footnotetext{
${ }^{1}$ Earth System Science Center, National Institute for Space Research, São José dos Campos, Brazil.

${ }^{2}$ Department of Austrian Lightning Detection and Information System, Austrian Electrotechnical Association, Vienna, Austria.

Copyright 2012 by the American Geophysical Union. 0148-0227/12/2011JD017135
}

applications [Berger et al., 1975; Anderson and Eriksson, 1980; Cooray, 2010].

[4] More recently, digital high-speed cameras have been used for similar purposes [e.g., Ballarotti et al., 2005; Saba et al., 2006; Campos et al., 2007; Biagi et al., 2009, 2010; Saraiva et al., 2010; Saba et al., 2010]. In this paper, we review some parameters of natural (not-triggered by a tower or a rocket) negative downward lightning based on previous accurate-stroke-count studies together with our data and compare this data with Berger's data of downward flashes. The parameters are: (parameter A) continuing current duration, (parameter B) time intervals between strokes, (parameter C) number of strokes per flash, and (parameter D) total flash duration. We will use one of the most common and useful statistical presentation of a parameter in science or engineering, which is the frequency (or probability) distribution.

[5] An accurate-stroke-count study identifies each returnstroke with a high confidence level, enabling better statistics for natural lightning parameters. The accurate-stroke-count studies discussed here provide more reliable information on some cloud-to-ground lightning parameters than studies based on lightning location system (LLS) data, for example. This is because some strokes may not be detected or misclassified by lightning location systems. Further, the continuing current duration is not detected by lightning location systems at all.

[6] In order to achieve reliable statistical knowledge of the natural downward lightning parameters, care must be taken to: (1) exclude any upward lightning, (2) distinguish between negative and positive downward flashes due to their different nature and characteristics and (3) ensure that all data sets are based on accurate-stroke-count studies. 
[7] Cianos and Pierce [1972] showed probability distributions for these four parameters (A-D), based on various data sets - including Berger's -, but without distinction between negative and positive polarities. Although Thomson [1980] determined probability distributions for these four parameters in natural flashes, it is not considered an accurate-stroke-count study [Rakov and Huffines, 2003]. Janischewskyj et al. [1997] presented such distributions for parameters (A-C) mainly based on data from upward lightning on towers. Anderson and Eriksson [1980] analyzed these three parameters, but considered both upward and downward flashes in their worldwide data summary. Berger's data from downward lightning are of special interest in terms of stroke current characterization [Berger et al., 1975; Berger, 1967].

\section{Used Data}

[8] Four past studies were already considered by Rakov and Huffines [2003] as accurate-stroke-count studies: (1) Kitagawa et al. [1962], in New Mexico (U.S.A.), (2) Rakov and Uman [1990a], in Florida (U.S.A), (3) Cooray and Pérez [1994], in Sweden, and (4) Cooray and Jayaratne [1994], in Sri Lanka. We consider our high-speed camera measurements in Vale do Paraíba (a valley in Sao Paulo State, Southeastern Brazil) as a fifth accurate-stroke-count study. In this present manuscript we compared these five studies, based on indirect measurements of natural downward lightning (electric field and/or optical records), with the direct current measurements of negative downward lightning on Monte San Salvatore (Switzerland) performed by K. Berger and colleagues [Berger et al., 1975; Berger, 1967], which have been the basis for the lightning protection standards. Considering that they had a good optical coverage and no strokes were missed (due to strokes to the ground and not to the tower), we consider Berger's downward lightning data on Monte San Salvatore as a sixth accurate-stroke-count study.

[9] Our measurements comprise 883 negative cloud-toground flashes (4,041 strokes) observed in 102 thunderstorm days. Two high-speed digital video cameras (a Red Lake Motion Scope 8000S and a FASTCAM 512 PCI 2k) with frame rates ranging from 1,000 to 8,000 frames/second were used by the Atmospheric Electricity Group (ELAT) to record images of cloud-to-ground (CG) flashes in Vale do Paraíba between January 2003 and March 2010. The sites used during the data acquisition are located in São José dos Campos $\left(23.212^{\circ} \mathrm{S} ; 45.867^{\circ} \mathrm{W}\right.$, altitude: $\left.635 \mathrm{~m}\right)$ and Cachoeira Paulista $\left(22.686^{\circ} \mathrm{S} ; 44.984^{\circ} \mathrm{W}\right.$, altitude: $\left.625 \mathrm{~m}\right)$ cities and were not used simultaneously. Both sites are located in the Vale do Paraíba, a valley in Sao Paulo State, which is well covered by the Brazilian Lightning Location System (BrasilDat). In order to identify the stroke polarity and peak current, we used the BrasilDat data. The stroke matching between camera and BrasilDat was done by GPS time synchronization (to accuracy better than $1 \mathrm{~ms}$ ). For more details on the instrumentation, see Saba et al. [2006, 2009].

[10] In order to enhance the accuracy of our data in terms of ground connection identification, avoiding cloud contamination, we selected only cloud-to-ground flashes (1) within $30 \mathrm{~km}$ of the observing point and, for polarity identification, (2) only flashes that had at least one stroke detected as a negative cloud-to-ground stroke by the LLS. The data set used by Saba et al. [2006] were partially included (only those records closer than $30 \mathrm{~km}$ ) in the data set used in this study. Saba et al. [2006] data were based on 1,000 frames/s videos (1.0 time exposure frames). In our more recent field campaigns (up to 2010), we could record, through faster cameras (up to 8,000 frames/s), video frames with $0.125 \mathrm{~ms}$ exposure time. For this present work, we standardized our time resolution in $1.0 \mathrm{~ms}$ for the time-dependent parameters (i.e., continuing current, interstroke time interval and total flash duration) but no video frames were neglected on the analysis that could affect stroke identification and, consequently, the parameter "number of strokes per flash."

[11] Kitagawa et al. [1962] used correlated electric field and moving-film camera records. The analyses of Rakov and Uman [1990a] were based on electric field records and optical coverage (multiple-station TV system). Cooray and Pérez [1994] and Cooray and Jayaratne [1994] used broadband electric field records.

\section{Discussion on the Statistics of Lightning Parameters}

[12] In the following sections, we present frequency distributions for parameters A-D of downward negative lightning based on data from several studies. As already done by Cianos and Pierce [1972], Berger et al. [1975] and Berger [1967], lightning parameters are assumed to be lognormal distributed. Depicted values from the lognormal fit of the studies mentioned in section 2 for the parameters presented in this work are shown in Table 1 and are discussed in the following.

[13] As calculated and suggested by Chowdhuri et al. [2005], the cumulative lognormal fittings for all four parameters distributions presented in this section were approximated to a simpler equation for the probability (\%) of a parameter $x$ :

$$
P(x)=100 /\left(1+(x / \text { median })^{a}\right),
$$

where $a$ is a fitted exponent. Such a function can be useful in certain engineering applications of computing values easily, e.g., dimensioning equipments and test procedures in power engineering.

\subsection{Continuing Current Duration}

[14] As already used in the literature, the nomenclature for the continuing current $(\mathrm{CC})$ duration ranges are: "long" $(\mathrm{t}>40 \mathrm{~ms})$, "short" $(10>\mathrm{t} \leq 40 \mathrm{~ms})$ and "very short" ( $\leq 10 \mathrm{~ms}$ ) [Shindo and Uman, 1989; Ballarotti et al., 2005]. For the CC duration, we compare results from our new data set with the results obtained by Kitagawa et al. [1962] in terms of frequency distribution. For this comparison, we applied $3 \mathrm{~ms}$ as a minimum possible $\mathrm{CC}$ duration in order to eliminate what could just be return-stroke pulse tails in our high-speed camera video records. Considering all ranges of CC ( $\geq 3 \mathrm{~ms})$, the median CC duration was $6 \mathrm{~ms}$ and the average was $31 \mathrm{~ms}$. Table 1 shows $5 \%, 50 \%$ and $95 \%$ values for all our three distributions $(\geq 3,>10$ and $>40 \mathrm{~ms})$ and corresponding values for Kitagawa et al. [1962] long CC distribution. 
Table 1. Summary for Negative Cloud-to-Ground Lightning Parameters A, B, C and D

\begin{tabular}{|c|c|c|c|c|c|c|c|c|}
\hline \multirow[b]{2}{*}{ Parameter Label/Reference } & \multirow[b]{2}{*}{ Geographic Location } & \multirow{2}{*}{$\begin{array}{l}\text { Number } \\
\text { of Storms }\end{array}$} & \multirow{2}{*}{$\begin{array}{l}\text { Number } \\
\text { of Events }\end{array}$} & \multirow{2}{*}{$\begin{array}{c}\text { Arithmetic } \\
\text { Mean } \\
\text { Values }\end{array}$} & \multirow{2}{*}{$\begin{array}{c}\text { SD } \\
\text { of } \ln (x)^{a}\end{array}$} & \multicolumn{3}{|c|}{$\begin{array}{l}\text { Percentage of Cases } \\
\text { Exceeding Tabulated } \\
\text { Values (According } \\
\text { to a Lognormal } \\
\text { Distribution) }^{\mathrm{b}}\end{array}$} \\
\hline & & & & & & $95 \%$ & $50 \%$ & $5 \%$ \\
\hline \multicolumn{9}{|l|}{ A: Continuing Current Duration (ms) } \\
\hline This Study ( $\geq 3 \mathrm{~ms})$ & Vale do Paraíba, Brazil & 102 & 2180 & 31 & 1.87 & $0.3^{\mathrm{c}}$ & 6 & 142 \\
\hline This Study ( $>10 \mathrm{~ms})$ & Vale do Paraíba, Brazil & 102 & 715 & 85 & 1.29 & $5^{\mathrm{c}}$ & 39 & 344 \\
\hline This Study (>40 ms) & Vale do Paraíba, Brazil & 102 & 304 & 173 & 0.69 & 44 & 137 & 429 \\
\hline Kitagawa et al. [1962] (>40 ms) & New Mexico, U.S.A. & 1 & 40 & 206 & 0.70 & 52 & 163 & 519 \\
\hline \multicolumn{9}{|l|}{ B: Interstroke Time Interval (ms) } \\
\hline Berger et al. $[1975]^{\mathrm{d}}$ & $\begin{array}{l}\text { Monte San Salvatore, } \\
\text { Switzerland }\end{array}$ & - & 133 & - & 1.06 & 7 & 33 & 150 \\
\hline Rakov et al. [1994] & Florida, U.S.A. & 3 & 270 & - & 0.80 & 16 & 60 & 226 \\
\hline This study & Vale do Paraíba, Brazil & 102 & 3147 & 92 & 0.92 & 13 & 59 & 270 \\
\hline \multicolumn{9}{|l|}{ C: Number of Strokes per Flash } \\
\hline Berger $[1967]^{\mathrm{f}}$ & $\begin{array}{l}\text { Monte San Salvatore, } \\
\text { Switzerland }\end{array}$ & - & 210 & 3.2 & 0.70 & $0.9^{\mathrm{c}}$ & 2.8 & 9.2 \\
\hline Cooray and Pérez $[1994]^{\mathrm{g}}$ & Uppsala, Sweden & 5 & 137 & 3.4 & 0.59 & 1.3 & 3.4 & 8.8 \\
\hline Cooray and Jayaratne [1994] & Colombo, Sri Lanka & 2 & 81 & 4.5 & 0.65 & 1.4 & 4.0 & 11.8 \\
\hline Kitagawa et al. $[1962]^{\mathrm{h}}$ & New Mexico, U.S.A. & 3 & 193 & 6.4 & 0.75 & 1.5 & 5.2 & 17.4 \\
\hline Rakov and Uman [1990a $]^{\mathrm{h}}$ & Florida, U.S.A. & 3 & 76 & 4.6 & 0.68 & 1.3 & 4.0 & 12.4 \\
\hline This study & Vale do Paraíba, Brazil & 102 & 883 & 4.6 & 0.54 & 1.9 & 4.6 & 11.2 \\
\hline \multicolumn{9}{|l|}{ D. Total Flash Duration (ms) } \\
\hline $\begin{array}{l}\text { Berger et al. }[1975] \\
\quad \text { (only multiple-stroke flashes) }{ }^{\mathrm{i}}\end{array}$ & $\begin{array}{l}\text { Monte San Salvatore, } \\
\text { Switzerland }\end{array}$ & - & 39 & - & 1.03 & 31 & 180 & 900 \\
\hline $\begin{array}{l}\text { This study (only } \\
\text { multiple-stroke flashes) }\end{array}$ & Vale do Paraíba, Brazil & 102 & 736 & 423 & 0.92 & 66 & 300 & 1366 \\
\hline
\end{tabular}

${ }^{a}$ Inferred standard deviation of $\ln (\mathrm{x})$ from the fitted distribution described in the right columns.

${ }^{\mathrm{b}}$ Values depicted from the lognormal fit of the distribution, supposing the parameter distributes as a lognormal.

${ }^{c}$ Extrapolated values from the lognormal fitting.

${ }^{\mathrm{d}}$ The large difference that is observed in Berger's results is due to the different definition of time interval used in his work (no-current interval). The mean value was not available.

${ }^{\text {e}}$ Values were calculated from geometric mean (60) and standard deviation of the logarithm in base 10 (0.35). The mean value was not available

f The number of storms involved in Berger's data was not available, but there were certainly at least several tens of storms involved (between years 1955-1963)

${ }^{\mathrm{g}}$ Values recalculated from histograms presented in original paper.

${ }^{\mathrm{h}}$ Adapted from Rakov and Huffines [2003].

i The mean value was not available.

[15] Out of the 883 flashes recorded, 395 (45\%) contained $\mathrm{CC}$ with duration greater than $10 \mathrm{~ms}$ and $47 \%$ of all strokes were followed by some CC (very-short, short or long CC). The probability distribution of CC duration for our data is presented in Figure 1. Shindo and Uman [1989] using electric field measurements and standard video cameras found that $37 \%$ of flashes contained $\mathrm{CC}$ with duration greater than $10 \mathrm{~ms}$ (Florida, 3 thunderstorm days). We have decided to consider these CC events (greater than $10 \mathrm{~ms}$ ) separately because, considering a typical $\mathrm{CC}$ amplitude of 100-200 A, the charge transfer involved in these long-lasting processes is equal to or greater than the charge of a typical return-stroke (1-5 Coulombs) [Rakov and Uman, 2003]. We observed in our data set that only $2.4 \%(19 / 809)$ of first strokes in multiple flashes was followed by long CC. This percentage is in agreement with the one found by Rakov and Uman [1990b] (2\%).

[16] Long continuing currents (duration longer than $40 \mathrm{~ms}$ ) are responsible for most serious lightning damage associated with thermal effects, such as burned-through ground wires and Optical Fiber Ground Wires (OPGW) of overhead power lines [IEC, 2003a; IEEE, 2009], blowing fuses used to protect distribution transformers, holes in the metal skins of aircrafts, etc. [see, e.g., Fisher and Plumer,
1977; M. A. Uman, 1984; Rakov and Uman, 1990b; Chisholm et al., 2001]. In Table 1, our data set is compared only with the results of Kitagawa et al. [1962] in terms of long CC due to the small data set of other available studies.

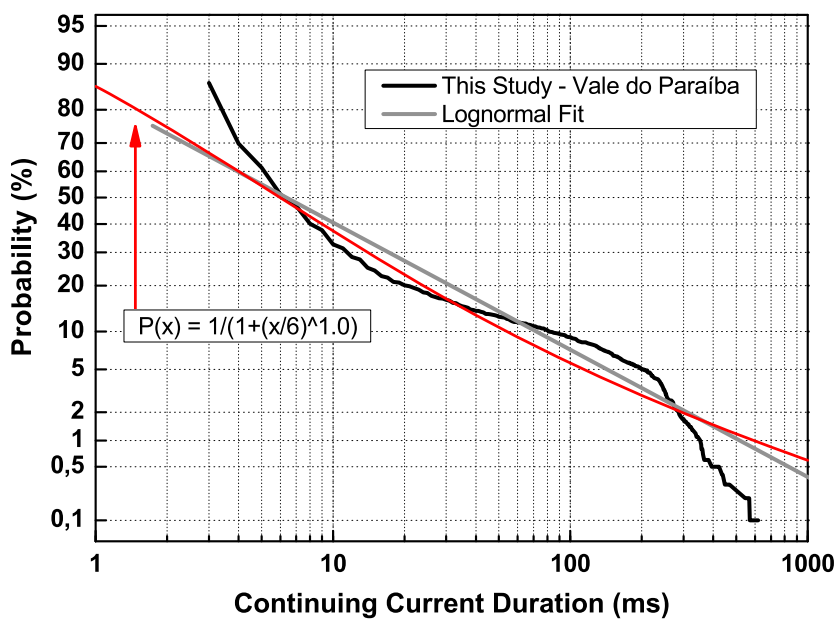

Figure 1. Probability distribution of $2,180 \mathrm{CC}$ durations greater or equal to $3 \mathrm{~ms}$ in Vale do Paraíba, Brazil. 


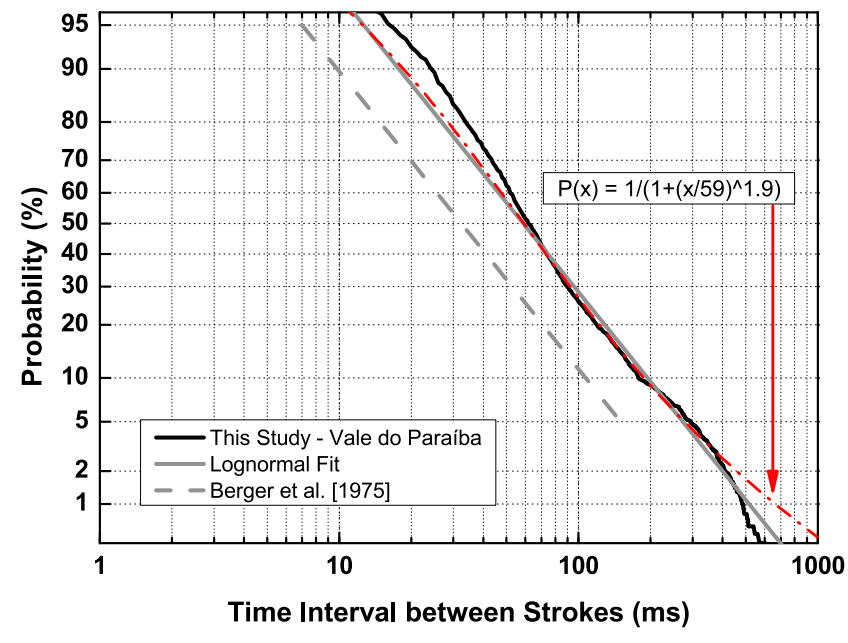

Figure 2. Probability distributions for interstroke intervals based on work by Berger et al. [1975] and on this study.

Although the results from Kitagawa et al. [1962] are slightly larger than our values, there is no significant difference between them (two sample independent t-Test at 0.05 level).

[17] The maximum value we measured for the CC duration was $714 \mathrm{~ms}$, which is the longest $\mathrm{CC}$ reported in the literature. Other extreme values were reported: one event by Ogawa [1995] (a value between 520 and $560 \mathrm{~ms}$ ) shown in a histogram and another one $(550 \mathrm{~ms})$ observed by Mazur et al. [1995] with a high-speed video camera. The IEC 60794-1-2 standard for lightning protection specifies a maximum $\mathrm{CC}$ duration of $500 \mathrm{~ms}$ for all four protection classes (I-IV) [IEC, 2003b]. We observed only 6 cases of continuing current longer than $500 \mathrm{~ms}$, representing $0.28 \%$ of the $2,180 \mathrm{CC}$ events (or $0.68 \%$ of the 883 flashes).

\subsection{Interstroke Time Interval}

[18] For our data set we analyzed 3,147 interstroke intervals and found $64 \mathrm{~ms}$ as the geometric mean of the interstroke interval. This geometric mean is in close agreement with previously published values, such as $65 \mathrm{~ms}$ by Shindo and Uman [1989], $60 \mathrm{~ms}$ by Rakov et al. [1994], and $61 \mathrm{~ms}$ by Saba et al. [2006]. Figure 2 shows the probability distribution and the lognormal fit for the whole set in comparison with results from Berger et al. [1975].

[19] According to Rakov and Uman [2003] and Fisher et al. [1993], the time interval presented by Berger et al. [1975] was actually the no-current interval between strokes, i.e., the interstroke interval excluding any $\mathrm{CC}$. Berger's different definition of interstroke time interval seems to be the main reason of his left-shifted distribution shown in Figure 2. Looking at Table 1, we can note the $50 \%$ higher median values found for our data set $(59 \mathrm{~ms})$ and Rakov et al. [1994] (60 ms), compared to $33 \mathrm{~ms}$ found by Berger et al. [1975]. Geometric mean values (which correspond to the median in a lognormal distribution [Uman, 1984]) closer to 60 ms were also found by Cooray and Pérez [1994] (48 ms) and by Cooray and Jayaratne [1994] (57 ms).

[20] According to our data and Rakov et al. [1994] in 95\% of cases, the interstroke interval exceeds 13-16 ms, and in $5 \%$ the interstroke interval exceeds 270-226 ms. Both values are greater than the values given by Berger et al.
[1975], suggesting that their distribution was thoroughly biased.

[21] A reanalysis of the interstroke intervals of strokes following the same channel in the data set of Saba et al. [2006] shows that approximately $19 \%$ of intervals between strokes that follow the same channel were shorter than $33 \mathrm{~ms}$. This is the time duration of the uncertainty window of standard video images even if odd and even fields of the frames are analyzed separately [Rakov and Huffines, 2003]. This shows the limitation of a standard video camera in the analysis of interstroke intervals.

[22] The longest interstroke interval ever reported in the literature was $782 \mathrm{~ms}$ [Saba et al., 2006]. We measured an extremely long interstroke interval of $776 \mathrm{~ms}$ of two strokes in the same ground connection with $714 \mathrm{~ms}$ of continuing current visible in this interval. An interstroke interval of $482 \mathrm{~ms}$ but involving two different ground connections was also observed. Another extreme interstroke interval value, $679 \mathrm{~ms}$, was reported by Mazur et al. [1995]. This large interval contained also the longest $\mathrm{CC}$ observed in their study. These records and other recent observations (M. M. F. Saba, personal communication, 2008) support the hypothesis that extreme-long interstroke intervals only occur when there is an extreme-long continuing current during this interval to sustain the lightning channel in the ground. Figure 2 shows that in $1.1 \%$ of the cases the interstroke interval exceeds $500 \mathrm{~ms}$, a value often applied by lightning detection networks to group strokes into the same flash.

[23] For Saba et al. [2006], the minimum values for interstroke time intervals were limited to $2 \mathrm{~ms}$, because the camera integrated the image in $1.0 \mathrm{~ms}$-exposure frames. Due to the same type of limitation and the standardization imposed on our data for this present study, our smallest interstroke interval is $1.0 \mathrm{~ms}$ for both same channel and new channel formation. The smallest interstroke interval based on electric field records found by Cooray and Pérez [1994] was $2.5 \mathrm{~ms}$ (sample size of 447) and by Cooray and Jayaratne [1994] was $0.98 \mathrm{~ms}$ (sample size of 284).

[24] In a detailed sub-millisecond analysis of the returnstroke electric field signature of 76 flashes, Rakov and Uman [1994] found some very short intervals between peaks in the range of $15 \mu \mathrm{s}$ to $3.3 \mathrm{~ms}$. According to them, interstroke intervals smaller than 100-200 $\mu$ s suggest a doublegrounded stroke (forked stroke), which could be also recognized when there is a double-grounded connection simultaneously for some milliseconds long, as observed, e.g., by Ballarotti et al. [2005]. Such sub-millisecond intervals, related to single- or double-grounded strokes, occurred in $18 \%$ of 76 flashes analyzed by Rakov and Uman [1994]. Considering strokes of same intensity, consecutive strokes with very short intervals and same ground termination point often would cause a larger effect in terms of damage when striking directly an equipment or a power line compared to a forked stroke.

\subsection{Number of Strokes per Flash (Flash Multiplicity)}

[25] According to the majority of the accurate-strokecount studies discussed here, about $75-80 \%$ of all negative cloud-to-ground flashes have more than one stroke (see Table 2). Comparing these studies in Table 1, the higher multiplicity values obtained by Kitagawa et al. [1962] are evident. In their analysis in $50 \%$ of cases, the number 
Table 2. Percentage of Negative Downward Single-Stroke Flashes Based on Accurate-Stroke-Count Studies: Berger's Direct Tower Measurements and Five Indirect Measurements ${ }^{\mathrm{a}}$

\begin{tabular}{lccc}
\hline \multicolumn{1}{c}{ Reference } & Geographical Location & Sample Size & Percent of Single-Stroke Flashes \\
\hline Berger et al. [1975] & Mt. San Salvatore, Switzerland & 210 & 39 \\
Kitagawa et al. [1962] & New Mexico, U.S.A. & 83 & 14 \\
Rakov and Uman [1990a] & Florida, U.S.A. & 76 & 17 \\
Cooray and Pérez [1994] & Uppsala, Sweden & 137 & 18 \\
Cooray and Jayaratne [1994] & Colombo, Sri Lanka & 81 & 21 \\
This study & Vale do Paraíba, Brazil & 883 & 17 \\
\hline
\end{tabular}

adapted from Rakov and Huffines [2003].

of strokes per flash exceeds 5.2 and in $5 \%$ the number of strokes per flash exceeds 17.4. Their observed percentage of single-stroke flashes of $14 \%$ is one of the lowest reported in the literature. Rakov and Huffines [2003] argued that: "the average number of strokes per flash in New Mexico (6.4) is the largest reported in the literature. It is possible that New Mexico cloud-to-ground flashes analyzed by Kitagawa et al. [1962] had access to several thunderstorm cells that were located side by side and were electrically active at the same time." Data from Lightning Location System (LLS) observations in Austria [Diendorfer et al., 1998], data from the U.S.A. [Rakov and Huffines, 2003] and data from an accurate-stroke-count study in Brazil [Saba et al., 2006] showed that there is a significant variation of this parameter for different thunderstorm days. According to Rakov and Huffines [2003], results obtained from two or three storms cannot represent properly typical values. As our data are based on 102 thunderstorm days occurring during 8 years, we consider that the values obtained are independent of storm type.

[26] Figure 3 shows the stroke multiplicity histogram for all the 883 negative downward flashes observed in Vale do Paraíba. The second criterion of the data selection in our methodology, as presented in section 2, requires the detection of at least one stroke of the flash by the LLS in order to identify the polarity information. This criterion introduced a bias: flashes with low values of stroke multiplicity (1-4) were naturally less selected (mean of $80 \%$ and minimum of

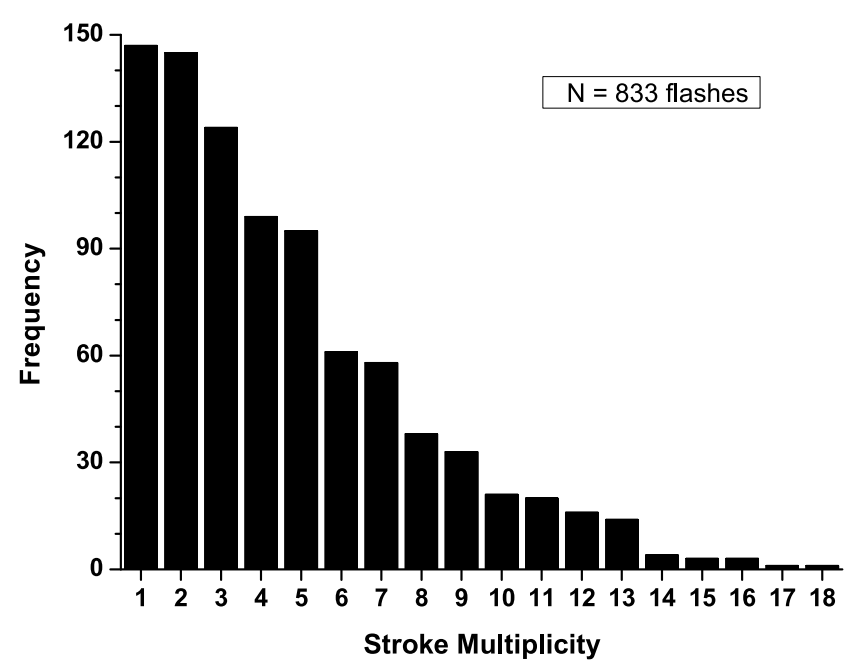

Figure 3. Histogram of stroke multiplicity for the 883 negative cloud-to-ground flashes observed in Vale do Paraíba, Brazil.
$67 \%$ for single-stroke flashes) when compared to the flashes with higher multiplicities (5-18) (mean of 95\%).

[27] Figure 4 shows the probability distribution of the number of strokes per flash observed on Vale do Paraíba compared with values obtained by Berger [1967]. There are significant differences between both curves (the percentage of single-stroke flashes found by Berger et al. [1975] is approximately two times greater than the values reported in other accurate studies (Table 2)). The IEEE Std. 1410-2010 [IEEE, 2011] presents a lognormal distribution with median of 2.4 and standard deviation of the natural logarithm of 0.96. Compared to the other distributions, it has the lowest values for 95 (hypothetical multiplicity 0.5 ) and $50 \%$ (2.4) and a similar value for $5 \%$ (11.6). The major limitation of this distribution seems to be the computation starting point for multiplicity $1(82 \%)$, which represents a considerable loss of the real distribution.

[28] Based on all these accurate-count-studies and considering the limitations of each technique applied to observe, one can recognize a certain pattern for the distribution of flash multiplicity: the $50 \%$ value is between 3 and 5 and the percentage of single-stroke flashes is in the range of $14-21 \%$, except for Berger's data (39\%) (Table 2).

[29] Data from video measurements show that the number of ground strike points per negative flash is around 1.7 [Kitagawa et al., 1962; Rakov et al., 1994; Saba et al., 2006]. An important engineering parameter can be directly

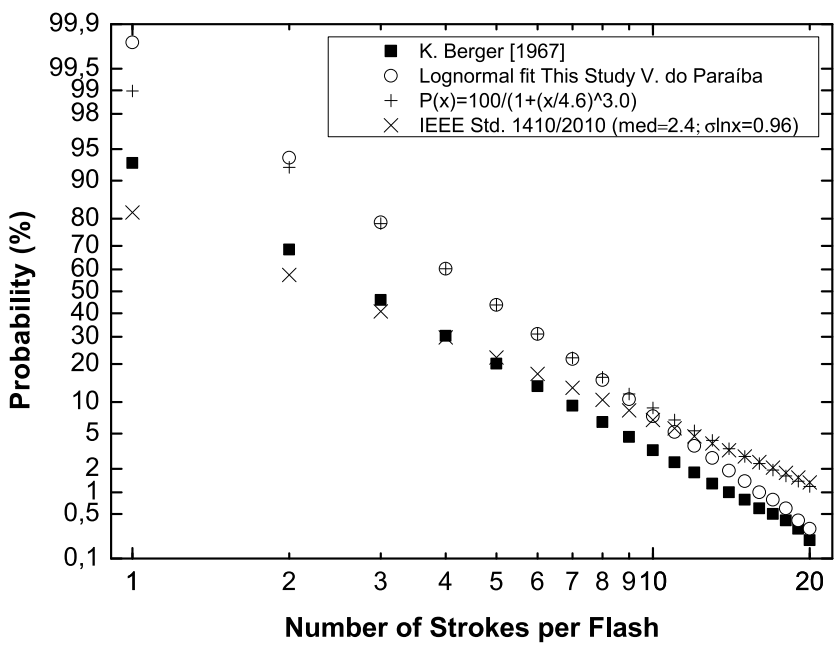

Figure 4. Probability distribution of the number of strokes per flash observed on Vale do Paraíba (Brazil) compared with obtained by Berger [1967], the fit $\mathrm{P}(\mathrm{x})$ and the distribution presented in IEEE Std. 1410-2010 [IEEE, 2011]. 


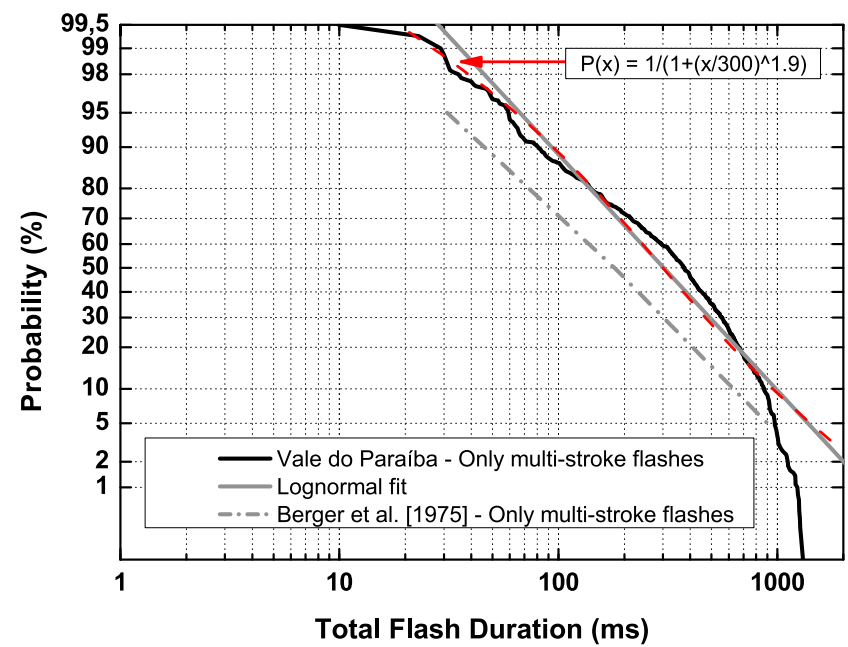

Figure 5. Total flash duration presented in terms of probability distribution for multistroke flashes observed on Vale do Paraíba and those reported by Berger et al. [1975].

obtained from ratio of the average number of strokes per flash and the average number of ground contacts per flash. We suggest to name this parameter as Number of Strokes per Ground Termination per Flash $\left(\mathrm{N}_{\mathrm{STF}}\right)$. This parameter would be more appropriate for Risk Analysis than the Ground Flash Density (GFD). For our measurements, with an average of 4.6 strokes per flash and an average of 1.7 contact points per flash, the $\mathrm{N}_{\mathrm{STF}}$ value is 2.7. Based on data obtained in Florida [Rakov et al., 1994; V. A. Rakov, personal communication, 2005], the $\mathrm{N}_{\mathrm{STF}}$ results in the same value: $4.6 / 1.67=2.7$. Thus, a conceivable value for $\mathrm{N}_{\mathrm{STF}}$ is expected to be in the range of 2-3. Analyzing Berger's tower data, one can note that his average number of strokes per flash (3.2) is actually the $\mathrm{N}_{\mathrm{STF}}$ (in case of a tower strikes, the number of ground contacts is always one), which is greater than 2.7.

\subsection{Total Flash Duration}

[30] The total flash duration calculated in this study is the time between the first stroke and the end of an eventual CC following the last stroke. The probability distribution for 736 multistroke flashes observed in Vale do Paraíba is presented in Figure 5. A comparison with Berger's data is also shown in Table 1 .

[31] When considering all flashes (single- and multistroke), Berger's 95\% (0.15 ms) and 50\% (13 ms) values are much smaller than those ones found in our measurements (36 and 244, respectively). Three possible reasons acting together for this discrepancy can be pointed out: (1) due to Berger's instrumentation with higher time resolution, the lowest durations are of the order of tens of microseconds for single strokes, whereas for the high-speed camera data the minimum duration value is $1.0 \mathrm{~ms}$; (2) the stroke duration (and thus, the flash duration for single-strokes) measured by $\mathrm{K}$. Berger was time-truncated on the half peak value on the tail [Rakov and Uman, 2003]; and (3) the very large percentage of single-stroke flashes found by Berger (39\%) [Berger, 1967; Berger et al., 1975].

[32] As mentioned above, this value is about two times greater than values usually observed in natural cloud-to- ground lightning normally [Saba et al., 2006] (see Table 2). For these reasons, we decided to compare only multiplestroke flashes.

[33] Comparing total flash duration distributions of multiple-stroke flashes, one can note certain similarity between results from our measurements presented here and the values reported by Berger [1967] and Berger et al. [1975] (see also Table 1). The sample size used in this study is approximately 19 times larger than in Berger's study [Berger et al., 1975]. Also, Diendorfer et al. [1998] found values of the same order for the flash duration (23 ms, $175 \mathrm{~ms}$ and $725 \mathrm{~ms}$ for $95 \%, 50 \%$ and 5\% respectively) based on more than 15 thousand flashes detected by the Austrian Lightning Detection and Information System - ALDIS.

[34] The maximum duration value observed by Saba et al. [2006] was $1,356 \mathrm{~ms}$ for a 16-stroke flash. Other extreme duration values were found by Kitagawa et al. [1962], $1,699 \mathrm{~ms}$ for a 12 -stroke flash and 1,928 ms for a 26-stroke flash. This value of $1,928 \mathrm{~ms}$ is the highest value reported in the literature (it is important to remember the possible limitation of their work mentioned in section 2.3). The maximum flash duration value we found was $1,430 \mathrm{~ms}$ for a 7 -stroke flash.

[35] We also found a good correlation between the mean flash duration and the number of strokes per flash (Figure 6). We selected only multiplicities up to 13 because for higher multiplicities the sample size was too small. We found a high determination coefficient $\left(\mathrm{R}^{2}=0.95\right)$, showing that the data are strongly correlated. A minimum flash duration per number of strokes was previously presented by Saba et al. [2006] and a similar evaluation for upward flashes was done by Janischewskyj et al. [1997].

\section{Conclusions}

[36] This paper reviews some lightning parameters for natural negative downward flashes. In contrast to some analyses that focused on upward flashes [Janischewskyj et al., 1997] and positives flashes [Cianos and Pierce,

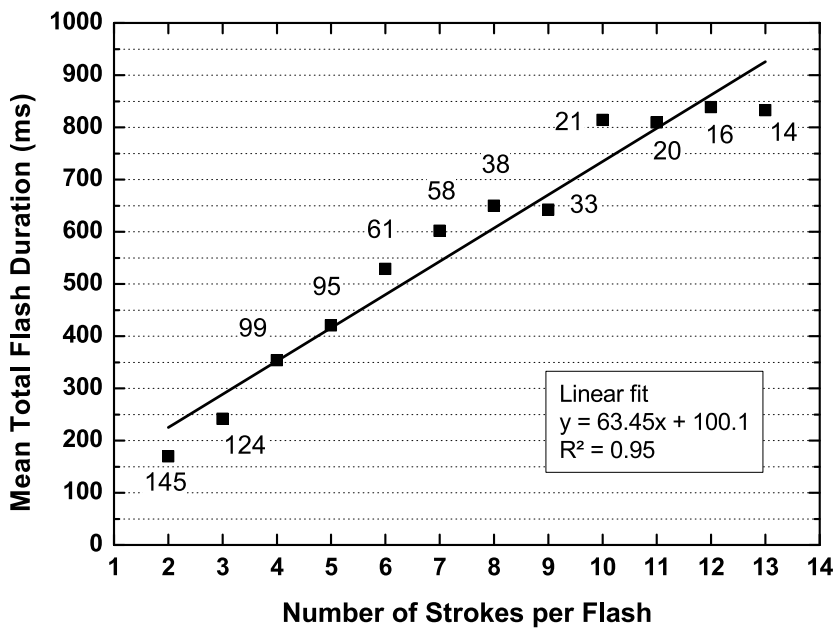

Figure 6. Mean total flash duration versus number of strokes per flash based on the 724 multiple-stroke flashes observed in Vale do Paraíba, Brazil. Sample sizes are indicated. 
1972], we excluded these statistics and evaluated only negative downward flash parameters.

[37] We discussed four parameters (CC duration, interstroke time interval, number of strokes per flash and total flash duration) and compared five accurate-stroke-count studies with Berger's tower measurements, which are the basis for the national and international standards on lightning protection. In general, a reasonable agreement between distributions of parameters $\mathrm{A}, \mathrm{B}, \mathrm{C}$ and $\mathrm{D}$ (for multiplestroke flashes) was found. Comparisons were performed based on the lognormal fit of the distributions.

[38] To the best of our knowledge, these results are also the first presented in terms of probability distribution related to natural negative cloud-to-ground lightning including results from different accurate-stroke-count studies obtained in different regions of the world.

[39] Also to the best of our knowledge, this is the first time that continuing current duration (parameter A) statistics are presented from a few to hundreds of milliseconds. We analyzed the $\mathrm{CC}$ duration in three different ranges $(\geq 3,>10$ and $>40 \mathrm{~ms})$. First, considering all the data $(\geq 3 \mathrm{~ms})$, we found an average of $31 \mathrm{~ms}$ and a median of $6 \mathrm{~ms}$. Second, considering only CC durations greater than $10 \mathrm{~ms}$ (CCs exhibiting already a significant charge), we found an average of $85 \mathrm{~ms}$ and a median of $39 \mathrm{~ms}$. Third, considering only values greater than $40 \mathrm{~ms}$, we found an average of $173 \mathrm{~ms}$ and a median of $137 \mathrm{~ms}$ based on our data. Similar results were obtained by Kitagawa et al. [1962] for this third range. It is important to have in mind that $\mathrm{CC}$ duration measurements (from electric field or optical/imaging techniques) are always underestimations to a certain extent because they might be affected by rain, daylight and/or distance between the measurement site and the flash.

[40] Regarding interstroke time intervals (parameter B), we show the clear left-shifted Berger's data [Berger, 1967] distribution when compared to the two accurate-stroke-count data available to this parameter, Rakov et al. [1994] and our data. Berger's interstroke intervals values of $5 \%, 50 \%$ and $95 \%$ are approximately $50 \%$ lower when compared to the respective values of the two referred studies. Berger's parameters for interstroke interval do not seem to properly represent the natural downward negative lightning.

[41] The distributions of number of strokes per flash (parameter C) presented by Berger [1967] and our measurements are based on a large data set. Although Berger's distribution is based on tower measurements, it is similar to our distribution. Saba et al. [2006] presented values of average flash multiplicities varying from thunderstorm to thunderstorm in the range of 2.2 to 6.0, supporting the hypothesis that some studies could be biased by the limited number of thunderstorms, which could be the case to the other accurate-stroke-count studies. However, all six distributions (lognormal fitted values) are very similar.

[42] Regarding total flash duration (parameter D), we focused only on the multiple-stroke flashes and we found reasonable similarity between Berger's data [Berger, 1967] and our data. His data, as in parameter interstroke time interval, is left-shifted, presenting lower values than those presented in our data.

[43] Parameters discussed in this paper are important to specify test procedures for surge arresters in power systems related to energy stresses, as well as to evaluate the performance of lightning location systems [Cummins et al., 1998; Pinto et al., 2006, 2007]. There is currently an ongoing discussion about single-impulse versus multiimpulse energy absorption of surge arrestors and also the impact of multi impulse stress caused by multi stroke flashes (B. Richter, personal communication, 2005). We found a linear relation between number of strokes per flash and the mean of total flash duration with a high correlation for multiplicities from 2 to 13 . This relation could be used to create a more realistic sequence of strokes for multiimpulse tests.

[44] More accurate-stroke-count studies should be done in different regions of the world in order to get information about the variation of lightning parameters in different climates. Further high-speed camera observations (frame rates of hundreds to thousands frames/sec.) should also be done in conjunction with broadband electric field measurements in order to improve the lightning statistics especially on a lessthan-one-millisecond scale.

[45] Acknowledgments. This work was supported in part by FAPESP under grant $02 / 10630-7$ and by CNPq under grant 475299 / 2003-5. The authors also thank E. C. Ferraz, A. C. V. Saraiva, L. Z. S. Campos, C. Schumann, J. Alves, R. B. G. da Silva, and S. F. Viegas for data collection and G. Diendorfer, V. A. Rakov, and W. Chisholm for fruitful discussions on the topics presented here.

\section{References}

Anderson, R. B., and A. J. Eriksson (1980), Lightning parameters for engineering application, Electra, 69, 65-102.

Ballarotti, M. G., M. M. F. Saba, and O. Pinto Jr. (2005), High-speed camera observations of negative ground flashes on a millisecond-scale, Geophys. Res. Lett., 32, L23802, doi:10.1029/2005GL023889.

Berger, K. (1967), Novel observations on lightning discharges: Results of research on Mount San Salvatore, J. Franklin Inst., 283(6), 478-525, doi:10.1016/0016-0032(67)90598-4.

Berger, K., R. B. Anderson, and H. Kröninger (1975), Parameters of lightning flashes, Electra, 41, 23-37.

Biagi, C. J., D. M. Jordan, M. A. Uman, J. D. Hill, W. H. Beasley, and J. Howard (2009), High-speed video observations of rocket-and-wire initiated lightning, Geophys. Res. Lett., 36, L15801, doi:10.1029/ 2009GL038525.

Biagi, C. J., M. A. Uman, J. D. Hill, D. M. Jordan, V. A. Rakov, and J. Dwyer (2010), Observations of stepping mechanisms in a rocket-andwire triggered lightning flash, J. Geophys. Res., 115, D23215, doi:10.1029/2010JD014616.

Campos, L. Z. S., M. M. F. Saba, O. Pinto Jr., and M. G. Ballarotti (2007), Waveshapes of continuing currents and properties of M-components in natural negative cloud-to-ground lightning from high-speed video observations, Atmos. Res., 84, 302-310, doi:10.1016/j.atmosres.2006.09.002.

Chisholm, W. A., J. P. Levine, and P. Chowdhuri (2001), Lightning arc damage to optical fiber ground wires (OPGW): parameters and test methods, paper presented at Power Engineering Society Summer Meeting, Power Eng. Soc., Vancouver, B. C., Canada.

Chowdhuri, P., et al. (2005), Parameters of lightning strokes: A review, IEEE Trans. Power Delivery, 20(1), 346-358, doi:10.1109/TPWRD. 2004.835039.

Cianos, N., and E. T. Pierce (1972), A ground-lightning environment for engineering usage, technical report, Stanford Res. Inst., Menlo Park, Calif.

Cooray, V. (2010), Lightning Protection, 1036 pp., Inst. of Eng. and Technol., London.

Cooray, V., and K. P. S. C. Jayaratne (1994), Characteristics of lightning flashes observed in Sri Lanka in the tropics, J. Geophys. Res., 99(D10), 21,051-21,056, doi:10.1029/94JD01519.

Cooray, V., and H. Pérez (1994), Some features of lightning flashes observed in Sweden, J. Geophys. Res., 99(D5), 10,683-10,688, doi:10.1029/93JD02366.

Cummins, K. L., M. J. Murphy, E. A. Bardo, W. L. Hiscox, R. B. Pyle, and A. E. Pifer (1998), A combined TOA/MDF technology upgrade of U.S. National Lightning Detection Network, J. Geophys. Res., 103(D8), 9035-9044, doi:10.1029/98JD00153. 
Diendorfer, G., W. Schulz, and V. A. Rakov (1998), Lightning characteristics based on data from the Austrian Lightning Locating System, IEEE Trans. Electromagn. Compat., 40(4), 452-464, doi:10.1109/15.736206.

Fisher, F. A. and J. A. Plumer (1977), Lightning Protection of Aircraft, $N A S A-R P-1008,550$ pp., Gov. Printing Off., Washington, D. C.

Fisher, R. J., G. H. Schnetzer, R. Thottappillil, V. A. Rakov, M. A. Uman, and J. D. Goldberg (1993), Parameters of triggered-lightning flashes in Florida and Alabama, J. Geophys. Res., 98, 22,887-22,902, doi:10.1029/ 93JD02293.

Ianoz, M. (2007), Review of new developments in the modeling of lightning electromagnetic effects on overhead lines and buried cables, IEEE Trans. Electromagn. Compat., 49(2), 224-236, doi:10.1109/TEMC.2007. 897149.

International Council on Large Electric Systems (CIGRE) (1997), Lightning exposure to structures and interception efficiency of air terminals, Doc. 118,16 pp., Paris.

International Electrotechnical Commission (IEC) (2003a), Optical fibre cables-Sectional specification: Aerial optical cables along electrica power lines, IEC 60794-4, Int. Electrotechn. Comm., Geneva, Switzerland.

International Electrotechnical Commission (IEC) (2003b), Optical fibre cables-Generic specification: Basic optical cable test procedures, IEC 60794-1-2, Int. Electrotechn. Comm., Geneva, Switzerland.

Institute of Electrical and Electronics Engineers (IEEE) (2009), IEEE standard for testing and performance for optical ground wire (OPGW) for use on electric utility power lines, IEEE 1138-2009, 50 pp., New York.

Institute of Electrical and Electronics Engineers (IEEE) (2011), IEEE guide for improving the lightning performance of electric power overhead distribution lines, IEEE 1410-2010, 63 pp., New York.

Janischewskyj, W., A. M. Hussein, V. Shostak, I. Russan, J.-X. Li, and J.-S. Chang (1997), Statistics of lightning strikes to the Toronto Canadian National Tower (1978-1995), IEEE Trans. Power Delivery, 12(3), 1210-1221, doi:10.1109/61.636949.

Kitagawa, N., M. Brook, and E. J. Workman (1962), Continuing currents in cloud-to-ground lightning discharges, J. Geophys. Res., 67(2), 637-647, doi:10.1029/JZ067i002p00637.

Mazur, V., P. R. Krehbiel, and X.-M. Shao (1995), Correlated highspeed video and interferometric observations of a cloud-to-ground flash, J. Geophys. Res., 100, 25,731-25,753, doi:10.1029/95JD02364.

Ogawa, T. (1995), Lightning currents, in Handbook of Atmospheric Electrodynamics, vol. I, edited by H. Voland, pp. 23-63, CRC Press, Boca Raton, Fla

Pinto, O., Jr., K. P. Naccarato, I. R. C. A. Pinto, W. A. Fernandes, and O. P. Neto (2006), Monthly distribution of cloud-to-ground lightning flashes as observed by lightning location systems, Geophys. Res. Lett., 33, L09811, doi:10.1029/2006GL026081.

Pinto, O., Jr., I. R. C. A. Pinto, and K. P. Naccarato (2007), Maximum cloud-to-ground lightning flash densities observed by lightning location systems in the tropical region: A review, Atmos. Res., 84, 189-200, doi:10.1016/j.atmosres.2006.11.007

Rakov, V. A. (2001), Transient response of a tall object to lightning, IEEE Trans. Electromagn. Compat., 43(4), 654-661, doi:10.1109/15.974646.

Rakov, V. A. (2003), A review of the interaction of lightning with tall objects, in Recent Research Developments in Geophysics, vol. 5, pp. 57-71, Res. Signpost, Trivandrum, India.
Rakov, V. A., and G. R. Huffines (2003), Return-stroke multiplicity of negative cloud-to-ground lightning flashes, J. Appl. Meteorol., 42, 1455-1462, doi:10.1175/1520-0450(2003)042<1455:RMONCL>2.0.CO;2.

Rakov, V. A., and M. A. Uman (1990a), Some properties of negative cloudto-ground lightning, paper presented at 20th International Conference on Lightning Protection, Swiss Electrotechn. Assoc., Interlaken, Switzerland.

Rakov, V. A., and M. A. Uman (1990b), Long continuing current in negative lightning ground flashes, J. Geophys. Res., 95(D5), 5455-5470, doi:10.1029/JD095iD05p05455.

Rakov, V. A., and M. A. Uman (1994), Origin of lightning electric field signatures showing two return-stroke waveforms separated in time by a millisecond or less, J. Geophys. Res., 99(D4), 8157-8165, doi:10.1029/ 94JD00165.

Rakov, V. A., and M. A. Uman (2003), Lightning: Physics and Effects, 687 pp., Cambridge Univ. Press, Cambridge, U. K.

Rakov, V. A., M. A. Uman, and R. Thottappillil (1994), Review of lightning properties from electric field and TV observations, J. Geophys. Res., 99, 10,745-10,750, doi:10.1029/93JD01205.

Saba, M. M. F., M. G. Ballarotti, and O. Pinto Jr. (2006), Negative cloud-to-ground lightning properties from high-speed video observations, J. Geophys. Res., 111, D03101, doi:10.1029/2005JD006415.

Saba, M. M. F., L. Z. S. Campos, E. P. Krider, and O. Pinto Jr. (2009), High-speed video observations of positive ground flashes produced by intracloud lightning, Geophys. Res. Lett., 36, L12811, doi:10.1029/ 2009GL038791.

Saba, M. M. F., W. Schulz, T. A. Warner, L. Z. S. Campos, C. Schumann, E. P. Krider, K. L. Cummins, and R. E. Orville (2010), High-speed video observations of positive lightning flashes to ground, J. Geophys. Res., 115, D24201, doi:10.1029/2010JD014330.

Samaras, K., C. Sandberg, C. J. Salmas, and A. Koulaxouzidis (2007), Electrical surge-protection devices for industrial facilities - A tutorial review, IEEE Trans. Ind. Appl., 43(1), 150-161, doi:10.1109/TIA.2006.886994.

Saraiva, A. C. V., M. M. F. Saba, O. Pinto, K. L. Cummins, E. P. Krider and L. Z. S. Campos (2010), A comparative study of negative cloud-toground lightning characteristics in São Paulo (Brazil) and Arizona (United States) based on high-speed video observations, J. Geophys. Res., 115, D11102, doi:10.1029/2009JD012604.

Shindo, T., and M. A. Uman (1989), Continuing current in negative cloudto-ground lightning, J. Geophys. Res., 94(D4), 5189-5198, doi:10.1029/ JD094iD04p05189.

Thomson, E. M. (1980), Characteristics of Port Moresby ground flashes, J. Geophys. Res., 85(C2), 1027-1036, doi:10.1029/JC085iC02p01027. Uman, M. A. (1984), The Lightning Discharge, Dover, Mineola, N. Y.

Visacro, S., and F. H. Silveira (2005), Lightning current waves measured at short instrumented towers: The influence of sensor position, Geophys. Res. Lett., 32, L18804, doi:10.1029/2005GL023255.

M. G. Ballarotti, C. Medeiros, O. Pinto Jr., and M. M. F. Saba, Earth System Science Center, National Institute for Space Research, São José dos Campos, SP 12.227-010, Brazil. (mauricio.ballarotti@inpe.br)

W. Schulz, Department of Austrian Lightning Detection and Information System, Austrian Electrotechnical Association, Kahlenberger Str. 2A, A-1190 Vienna, Austria. 